\title{
Low-Cost Cultivation and Sporulation of Alkaliphilic Bacillus sp. Strain AK13 for Self-Healing Concrete
}

\author{
Minyoung Hong, Wonjae Kim, and Woojun Park ${ }^{*}$ \\ Laboratory of Molecular Environmental Microbiology, Department of Environmental Science and Ecological Engineering, Korea University, \\ Seoul 02841, Republic of Korea
}

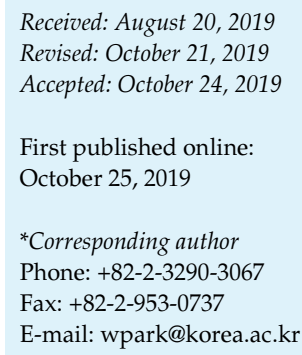

The alkaliphilic, calcium carbonate precipitating Bacillus sp. strain AK13 can be utilized in concrete for self-repairing. A statistical experimental design was used to develop an economical medium for its mass cultivation and sporulation. Two types of screening experiment were first conducted to identify substrates that promote the growth of the AK13 strain: the first followed a one-factor-at-a-time factorial design and the second a two-level full factorial design. Based on these screening experiments, barley malt powder and mixed grain powder were identified as the substrates that most effectively promoted the growth of the AK13 strain from a range of 21 agricultural products and by-products. A quadratic statistical model was then constructed using a central composite design and the concentration of the two substrates was optimized. The estimated growth and sporulation of Bacillus sp. strain AK13 in the proposed medium were $3.08 \pm 0.38 \times 10^{8}$ and $1.25 \pm 0.12 \times 10^{8} \mathrm{CFU} / \mathrm{ml}$, respectively, which meant that the proposed low-cost medium was approximately 45 times more effective than the commercial medium in terms of the number of cultivatable bacteria per unit price. The spores were then powdered via a spray-drying process to produce a spore powder with a spore count of $2.0 \pm 0.7 \times 10^{9} \mathrm{CFU} / \mathrm{g}$. The AK13 spore powder was mixed with cement paste, yeast extract, calcium lactate, and water. The yeast extract and calcium lactate generated the highest $\mathrm{CFU} / \mathrm{ml}$ for AK13 at a 0.4:0.4 ratio compared to 0.4:0.25 (the original ratio of the B4 medium) and 0.4:0.8. Twenty-eight days after the spores were mixed into the mortar, the number of vegetative cells and spores of the AK13 strain had reached $10^{6} \mathrm{CFU} / \mathrm{g}$ within the mortar. Cracks in the mortar under $0.29 \mathrm{~mm}$ were healed in 14 days. Calcium carbonate precipitation was observed on the crack surface. The mortar containing the spore powder was thus concluded to be effective in terms of healing micro-cracks.

Keywords: Economical medium, agricultural products, statistical design of experiments, spray dryer, crack healing material, calcium carbonate precipitation

\section{Introduction}

About 25 billion metric tons of Portland cement concrete are produced each year worldwide for use as a building material because of its economical nature and high rigidity [1-3]. However, concrete can crack due to internal dry shrinkage, age, and physical shocks, resulting in erosion and reduced strength [4]. Maintenance work is thus essential to prevent damage to the concrete due to cracks, but the repair process is expensive and time-consuming, especially for sections with poor accessibility, such as cracks on the underside of a bridge, the wall of a dam, and the middle of a tunnel. To overcome these limitations, selfhealing materials that can be added to concrete have been studied. These materials, which include polymers, ceramics, metals, and coating agents, can autonomously heal or seal cracks within the concrete by reacting with water $[5,6]$. Although many self-healing materials have been proposed, the application of bacteria in self-healing concrete has been investigated globally as an 
environmentally friendly alternative. Bacteria can be isolated from a variety of environmental sources, including marine sources, the rhizosphere of Miscanthus sacchariflorus, limestone, and soil, and used as self-healing agents in concrete because they microbiologically induce calcium carbonate precipitation, increase the $\mathrm{pH}$, and form spores [7-10]. Cracks in concrete that contains bacteria (i.e., bioconcrete) can thus be sealed by the calcium carbonate precipitated near the bacterial cell wall.

Media components account for up to $60 \%$ of the cost of producing bacteria [11]. Therefore, new media sources are required to replace existing commercial media such as Difco sporulation medium in order for bioconcrete to become more practical. In previous studies, agricultural products or agricultural/industrial byproducts have been utilized to create economically viable media [12-16]. For example, corn steep liquor, lactose mother liquor, and chicken manure effluent have been used as the main substrates in alternative low-cost media that can be directly applied to concrete [17-19]. However, the bacteria investigated in these previous studies were applied in a vegetative state, meaning that they cannot survive for long periods of time in the concrete due to the high alkalinity and salinity $[11,20,21]$.

In this study, we used the halotolerant and alkaliphilic Bacillus sp. AK13 that can survive at $\mathrm{pH}$ levels up to 13, which makes it suitable for use in strongly alkaline (i.e., $\mathrm{pH}$ 12 to 13) conditions of concrete [22]. The AK13 strain was grown and sporulated in a low-cost medium developed by applying a statistical design of experiments (DOE). Spores of the AK13 strain were spray-dried from the culture solution to produce a spore powder that was then mixed with mortar. Most probable number (MPN) test was then conducted to confirm the number of viable spores in the AK13-containing mortar. The mortar was also immersed in water and observed with a microscope to determine the healing rate and the amount of calcium carbonate that precipitated in the cracks using an imaging station program.

\section{Materials and Methods}

\section{Microorganism and Seed Culture Preparation}

Bacillus sp. AK13 was isolated from the rhizosphere of Miscanthus sacchariflorus near Seongbukcheon in South Korea [22]. The AK13 strain was inoculated in Luria-Bertani (LB) broth, which consisted of $0.5 \%$ yeast extract (Bioshop), $1 \%$ tryptone (Bioshop), and 1\% sodium chloride (Sigma-Aldrich), and incubated for $24 \mathrm{~h}$ in an orbital shaker (BioNex Solutions, USA) at $30^{\circ} \mathrm{C}$ and
$220 \mathrm{rpm}$. Sterilized $100 \%$ glycerol (Junsei) was then mixed with the AK13 cultivated in the LB broth at a 1:1 ratio in a 1.8-ml vial (Corning, USA) and maintained at $-70^{\circ} \mathrm{C}$ for long-term storage. For use in experiments, a loopful of the AK13 stock culture was streaked across an LB agar plate $(\mathrm{pH} 8)$ made from $0.25 \mathrm{~g} / 1 \mathrm{LB}$ broth powder and $0.15 \mathrm{~g} / 1$ agar powder (Junsei) and then incubated at $30^{\circ} \mathrm{C}$ for $24 \mathrm{~h}$. After colonies had begun to form, the cell stock was kept at $4^{\circ} \mathrm{C}$ for storage.

A test tube containing $5 \mathrm{ml}$ of LB broth ( $\mathrm{pH} 8$ ) was inoculated with a colony from the cell stock and cultured in a rotary shaker $\left(30^{\circ} \mathrm{C}, 220 \mathrm{rpm}\right)$ for about $24 \mathrm{~h}$ until the AK13 strain had completely entered a stationary phase. Following this, $0.5 \mathrm{ml}$ of the seed culture was transferred into a 1.5-ml microtube (Axygen), centrifuged, and washed twice with PBS buffer containing $1.44 \mathrm{~g} / \mathrm{l}$ $\mathrm{Na}_{2} \mathrm{HPO}_{4}, 0.24 \mathrm{~g} / 1 \mathrm{KH}_{2} \mathrm{PO}_{4}, 0.8 \mathrm{~g} / 1 \mathrm{NaCl}$, and $0.2 \mathrm{~g} / 1 \mathrm{KCl}$. The inoculum of the AK13 strain was then added to the experimental media at a density of $10^{5} \mathrm{CFU} / \mathrm{ml}$. This inoculation method was the same for all experiments.

Cultivation Methods and Estimation of the Growth and Sporulation of the AK13 Strain

The experimental medium $(20 \mathrm{ml})$ was transferred to Erlenmeyer flasks and cultivated at $30^{\circ} \mathrm{C}$ and $220 \mathrm{rpm}$ in a rotary shaker. All of the low-cost materials were autoclaved at $121^{\circ} \mathrm{C}$ for $20 \mathrm{~min}$, and inorganic salt solutions were filtered through $0.22 \mu \mathrm{m}$ membrane filters (Sartorius). The $\mathrm{pH}$ of the media experiments was set at approximately 10.5 using $\mathrm{Na}_{2} \mathrm{CO}_{3}$ (Junsei) unless otherwise noted. The number of vegetative cells and spores was estimated based on colony-forming units (CFUs). Culture fluid incubated for $24 \mathrm{~h}$ for nutritional cells and $72 \mathrm{~h}$ for spores was serially diluted from $10^{-1}$ to $10^{-6}$ or $10^{-7}$, and each dilution was dropped on a 20-ml petri dish of LB agar in duplicate. Pasteurization was conducted to inactivate the vegetative cells and measure the spore yields. Colony counts were confirmed after incubating the plates at $30^{\circ} \mathrm{C}$ for $24 \mathrm{~h}$ for the vegetative cells and at room temperature for $72 \mathrm{~h}$ for the spores. All of the experiments were carried out in triplicate.

\section{One-Factor-at-a-Time Approach as the Primary Screening Method for the Proposed Substrates}

All the low-cost substrates tested in this study were purchased or obtained from local markets and are summarized in Fig. 1A. The one-factor-at-a-time (OFAT) approach, a screening process that involves changing only one of the tested substrates at a time while the other conditions remain fixed, is often adopted in the early stages of experiments to determine which materials are the most effective for use in the low-cost medium by comparing the degree of growth and sporulation between them [12, 23, 24]. Modified M9 medium containing 6 g/l Na $\mathrm{HPO}_{4}, 3 \mathrm{~g} / 1 \mathrm{KH}_{2} \mathrm{PO}_{4}$, $1 \mathrm{~g} / 1 \mathrm{NH}_{4} \mathrm{Cl}, 2 \mathrm{~g} / 1$ glucose, $0.5 \mathrm{~g} / 1 \mathrm{MgSO}_{4}$, and $0.01 \mathrm{~g} / 1 \mathrm{CaCl}_{2}$ was used as the base medium. Glucose and $\mathrm{NH}_{4} \mathrm{Cl}$ were added to the M9 media as carbon and nitrogen sources, respectively, and this was used in both the control and experimental media with $1 \%$ of 

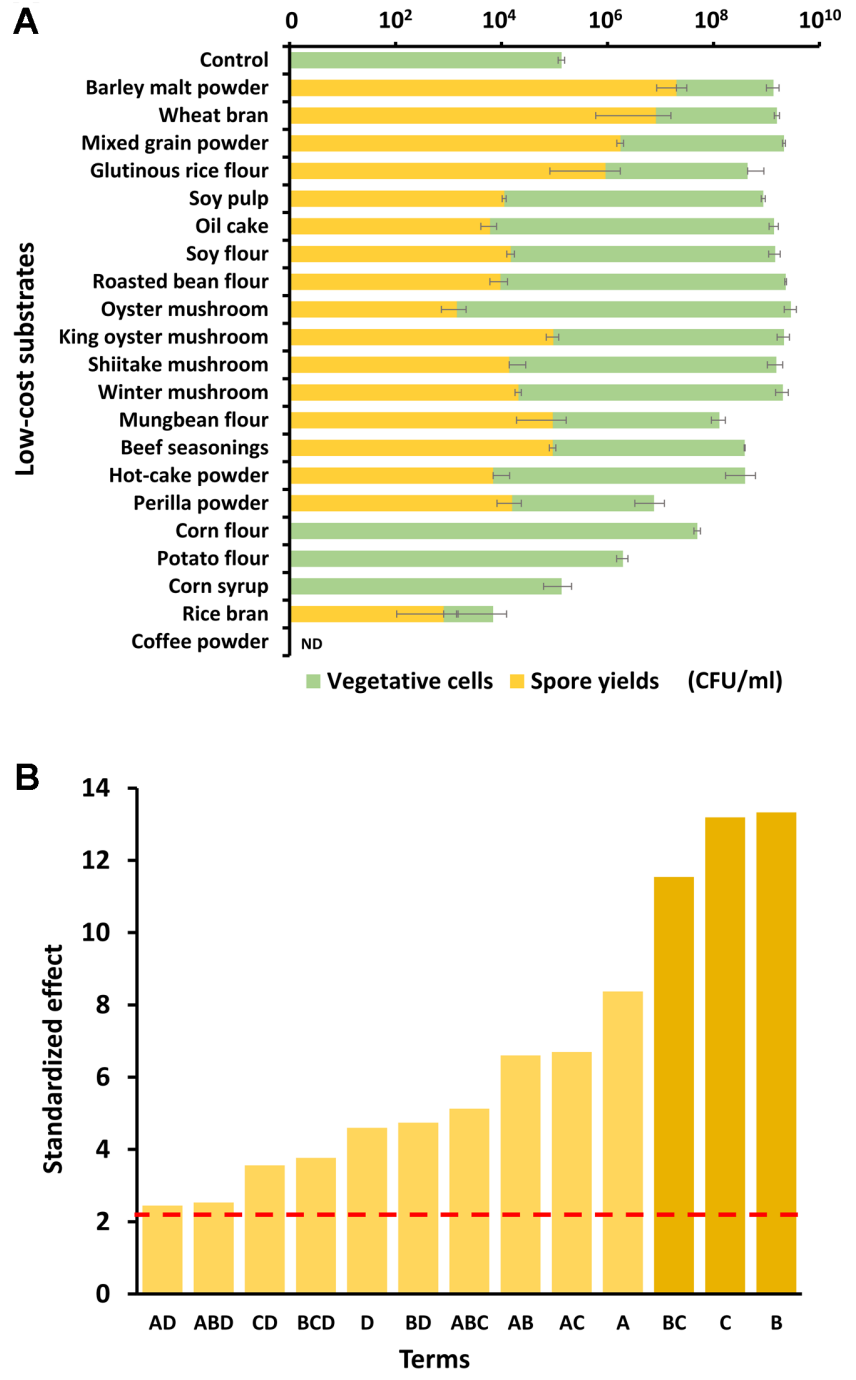

Fig. 1. Two types of screening experiment.

(A) One-factor-at-a-time approach and the effects of the tested factors on cultivation and sporulation. The error bars represent the standard deviation of the triplicates. ND: not detected. (B) Pareto chart for the contributions of the four main substrates to the growth of the AK13 strain in a two-level full factorial design. A, wheat bran; B, barley malt powder; $C$, mixed grain powder; $D$, glutinous rice powder. The dotted line indicates the point at which the $p$-value reaches 0.05 . Each bar standardizes the main effects of each factor on the growth of the AK13 strain or the interactions between or among the factors.

one of the tested substrates.

\section{Secondary Screening Using a Two-Level Full Factorial Design}

In the OFAT method, four factors are generally independently selected. A two-level factorial design is thus useful when there are no more than four factors in the early stages of the experiment; it is typically adopted to select two of the four factors as a secondary
Table 1. Design table for the two-level full factorial design and the corresponding results.

\begin{tabular}{|c|c|c|c|c|c|}
\hline \multirow[b]{2}{*}{$\begin{array}{c}\text { Standard } \\
\text { order }\end{array}$} & \multicolumn{4}{|c|}{ Factors $(\%, \mathrm{w} / \mathrm{v})$} & \multirow[b]{2}{*}{$\begin{array}{c}\text { Vegetative } \\
\text { cells } \\
(\log \mathrm{CFU} / \mathrm{ml})\end{array}$} \\
\hline & $\begin{array}{l}\text { Wheat } \\
\text { bran } \\
\text { (A) }\end{array}$ & $\begin{array}{l}\text { Barley } \\
\text { malt } \\
\text { powder } \\
\text { (B) }\end{array}$ & $\begin{array}{l}\text { Mixed } \\
\text { grain } \\
\text { powder } \\
\text { (C) }\end{array}$ & $\begin{array}{l}\text { Glutinous } \\
\text { rice flour } \\
\text { (D) }\end{array}$ & \\
\hline 1 & $-1(0.5)$ & $-1(0.5)$ & $-1(0.5)$ & $-1(0.5)$ & 5.68 \\
\hline 2 & $+1(2.0)$ & $-1(0.5)$ & $-1(0.5)$ & $-1(0.5)$ & 7.23 \\
\hline 3 & $-1(0.5)$ & $+1(2.0)$ & $-1(0.5)$ & $-1(0.5)$ & 6.97 \\
\hline 4 & $+1(2.0)$ & $+1(2.0)$ & $-1(0.5)$ & $-1(0.5)$ & 8.30 \\
\hline 5 & $-1(0.5)$ & $-1(0.5)$ & $+1(2.0)$ & $-1(0.5)$ & 7.21 \\
\hline 6 & $+1(2.0)$ & $-1(0.5)$ & $+1(2.0)$ & $-1(0.5)$ & 8.65 \\
\hline 7 & $-1(0.5)$ & $+1(2.0)$ & $+1(2.0)$ & $-1(0.5)$ & 9.03 \\
\hline 8 & $+1(2.0)$ & $+1(2.0)$ & $+1(2.0)$ & $-1(0.5)$ & 9.51 \\
\hline 9 & $-1(0.5)$ & $-1(0.5)$ & $-1(0.5)$ & $+1(2.0)$ & 5.63 \\
\hline 10 & $+1(2.0)$ & $-1(0.5)$ & $-1(0.5)$ & $+1(2.0)$ & 7.52 \\
\hline 11 & $-1(0.5)$ & $+1(2.0)$ & $-1(0.5)$ & $+1(2.0)$ & 7.81 \\
\hline 12 & $+1(2.0)$ & $+1(2.0)$ & $-1(0.5)$ & $+1(2.0)$ & 8.80 \\
\hline 13 & $-1(0.5)$ & $-1(0.5)$ & $+1(2.0)$ & $+1(2.0)$ & 6.46 \\
\hline 14 & $+1(2.0)$ & $-1(0.5)$ & $+1(2.0)$ & $+1(2.0)$ & 8.57 \\
\hline 15 & $-1(0.5)$ & $+1(2.0)$ & $+1(2.0)$ & $+1(2.0)$ & 9.31 \\
\hline 16 & $+1(2.0)$ & $+1(2.0)$ & $+1(2.0)$ & $+1(2.0)$ & 9.80 \\
\hline 17 & $0(1.25)$ & $0(1.25)$ & $0(1.25)$ & $0(1.25)$ & 8.11 \\
\hline 18 & $0(1.25)$ & $0(1.25)$ & $0(1.25)$ & $0(1.25)$ & 7.91 \\
\hline 19 & $0(1.25)$ & $0(1.25)$ & $0(1.25)$ & $0(1.25)$ & 7.47 \\
\hline 20 & $0(1.25)$ & $0(1.25)$ & $0(1.25)$ & $0(1.25)$ & 7.32 \\
\hline
\end{tabular}

screening process [23]. A two-level full factorial design involves setting two concentrations for each substrate and conducting experiments on the resulting combinations. The design table for all of the possible combinations of concentrations for each of the four substrates is shown in Table 1. The experiment was conducted by adding sterilized distilled water to flasks containing a specified amount of the tested substrates.

\section{Central Composite Design Based on Response Surface Methodology}

Response surface methodology (RSM) allows the curvature of the data to be determined and the optimal concentration of the low-cost substrates that maximize growth or sporulation to be identified. A central composite design (CCD), which is a useful tool in RSM, was adopted. The concentrations of the substrates used in the experiment and the design table are presented in Table 2. The linear and quadratic regression models for the dependent variables are as follows:

$$
\mathrm{Y}=\beta_{0}+\sum_{\mathrm{i}=1}^{2} \beta_{\mathrm{i}} \mathrm{X}_{\mathrm{i}}+\sum_{\mathrm{i}=1}^{2} \beta_{\mathrm{i}} \mathrm{X}_{\mathrm{i}}^{2}+\sum_{\mathrm{i}<\mathrm{j}=2}^{2} \beta_{\mathrm{ij}} \mathrm{X}_{\mathrm{i}} \mathrm{X}_{\mathrm{j}}
$$


Table 2. Design table for the central composite design and the corresponding results.

\begin{tabular}{ccccc}
\hline & \multicolumn{2}{c}{ Factors $(\%, \mathrm{w} / \mathrm{v})$} & \multicolumn{2}{c}{ Results } \\
\cline { 2 - 5 } $\begin{array}{c}\text { Standard } \\
\text { order }\end{array}$ & $\begin{array}{c}\text { Barley } \\
\text { malt } \\
\text { powder } \\
\end{array}$ & $\begin{array}{c}\text { Mixed } \\
\text { grain } \\
\text { powder } \\
\left(\mathrm{X}_{2}\right)\end{array}$ & $\begin{array}{c}\text { Vegetative } \\
\text { cells } \\
(\log \text { CFU } / \mathrm{ml})\end{array}$ & $\begin{array}{c}\text { Spore yields } \\
(\log \text { CFU } / \mathrm{ml})\end{array}$ \\
\hline 1 & $-1(2.0)$ & $-1(2.0)$ & 8.52 & 7.03 \\
2 & $+1(5.0)$ & $-1(2.0)$ & 9.52 & 6.25 \\
3 & $-1(2.0)$ & $+1(5.0)$ & 9.43 & 5.86 \\
4 & $+1(5.0)$ & $+1(5.0)$ & 9.48 & 6.07 \\
5 & $0(3.5)$ & $0(3.5)$ & 9.34 & 5.89 \\
6 & $0(3.5)$ & $0(3.5)$ & 9.4 & 5.94 \\
7 & $0(3.5)$ & $0(3.5)$ & 9.51 & 5.99 \\
8 & $-\alpha(1.38)$ & $0(3.5)$ & 8.21 & 6.76 \\
9 & $+\alpha(5.62)$ & $0(3.5)$ & 9.61 & 5.80 \\
10 & $0(3.5)$ & $-\alpha(1.38)$ & 8.52 & 6.94 \\
11 & $0(3.5)$ & $+\alpha(5.62)$ & 9.55 & 5.95 \\
12 & $0(3.5)$ & $0(3.5)$ & 9.53 & 6.51 \\
13 & $0(3.5)$ & $0(3.5)$ & 9.51 & 5.95 \\
14 & $0(3.5)$ & $0(3.5)$ & 9.54 & 5.78 \\
\hline
\end{tabular}

$\mathrm{Y}$ and $\mathrm{X}$ represent the dependent variables (growth or spore yields) and independent variables, respectively, while $\beta_{0}, \beta_{\mathrm{i}}$, and $\beta_{\mathrm{ij}}$ are the constant, coefficient of the independent variable, and interaction between two independent variables, respectively [25]

\section{Statistical Analysis}

Minitab software version 14 (Minitab Inc., USA) was used to conduct analysis of variance (ANOVA) to evaluate the development of the economical media development, to form a Pareto chart for two-level full factorial design, and to test the second-order (quadratic) model for the central composite design.

\section{Confirmation Experiment and Comparison with a Commercial Medium}

The proposed low-cost medium was optimized to have a concentration that maximized spore production using the central composite design. In order to further promote spore production, the following inorganic salts were added: $164 \mathrm{mg} / \mathrm{l} \mathrm{Ca}\left(\mathrm{NO}_{3}\right)_{2}$, $15 \mathrm{mg} / 1 \mathrm{FeCl}_{3}$, and $10 \mathrm{mg} / 1 \mathrm{ZnSO}_{4}[26,27]$. To evaluate the effectiveness of the proposed medium, it was compared to the existing commercial Difco sporulation medium (DSM), which is composed of $8 \mathrm{~g} / 1$ nutrient broth (Difco), $1 \mathrm{~g} / 1 \mathrm{KCl}$, and $0.25 \mathrm{~g} / 1$ $\mathrm{MgSO}_{4}$. The DSM was set at $\mathrm{pH} 8 \pm 0.1$ using $\mathrm{NaOH}$ and autoclaved at $121^{\circ} \mathrm{C}$ for $20 \mathrm{~min}$. Inorganic salts $(164 \mathrm{mg} / \mathrm{l}$ $\mathrm{Ca}\left(\mathrm{NO}_{3}\right)_{2}, 1.26 \mathrm{mg} / 1 \mathrm{MnCl}_{2}$, and $0.15 \mathrm{mg} / 1 \mathrm{FeSO}_{4}$ ) were then added in the form of filter-sterilized solutions. The growth and spore yields of AK13 were measured after $72 \mathrm{~h}$ of incubation in both the proposed low-cost medium and DSM.

\section{Preparation of Spore Powder Via a Spray-Drying Process}

AK13 spore powder was produced using an SD-Basic model spray dryer (LabPlant, UK). The culture medium was passed through a sieve once to prevent the nozzle from clogging during spray drying. The process conditions consisted of an inlet temperature of $165^{\circ} \mathrm{C}$, an airflow volume of $1.8 \mathrm{MPa}$, and $50 \%$ of full pump speed $(17.5 \mathrm{ml} / \mathrm{min})$. The outlet temperature was maintained at $85 \pm 2^{\circ} \mathrm{C}$ throughout the process. The spray dryer was preheated for $10 \mathrm{~min}$ before use. After the culture medium had been completely exhausted, the powder on the wall of the collection container and collector was scraped out with a spoon and put in 50-ml conical tubes (SPL Life Science, Korea) and stored at room temperature.

Calcium Carbonate Quantification and the Production of AK13Containing Mortar

AK13 was added to $100 \mathrm{ml}$ of modified B4 medium $(0.4 \mathrm{~g} / \mathrm{l}$ yeast extract and $0.4 \mathrm{~g} / \mathrm{l}$ calcium lactate) in a 250 -ml flask, with $1 \mathrm{M} \mathrm{NaOH}$ used to adjust the solution to $\mathrm{pH}$ 8. The flasks were incubated with agitation at $220 \mathrm{rpm}$ and $30^{\circ} \mathrm{C}$. To harvest the calcium carbonate, the solution was heated to $80^{\circ} \mathrm{C}$ for $10 \mathrm{~min}$ and microwaved twice at 1-min intervals. The samples were then centrifuged at 7,830 rpm for $10 \mathrm{~min}$ and washed in distilled water (DW) before a further round of centrifugation at 7,830 rpm. After draining the supernatant, the pellets were dried at $45^{\circ} \mathrm{C}$ for a day and weighed. The spore powder, yeast extract, and calcium lactate were mixed with ordinary Portland cement (OPC) and ISO standard sand (ISO 679: 2009). The mortar specimen was $40 \times 40 \times$ $10 \mathrm{~mm}^{3}$. The selection of the nutrient components was referenced from a modified B4 medium (yeast extract and calcium-lactate). The components of the B4 medium help to test microbially induced calcite crystal production [28]. The nutrient and spore powder ratio to the weight of the cement was $1.25 \%$ and $2.50 \%$, respectively.

\section{In situ Survival Test and Optical Crack-Healing Measurement}

Mortar specimens were ground to a powder and diluted at $1 / 10$ in PBS solution. The samples were vortexed for $5 \mathrm{~min}$ and centrifuged once for $10 \mathrm{~min}$ at $160 \mathrm{rpm}$. The harvested supernatant was diluted in LB medium $(\mathrm{pH} 8)$ and dispensed in 48 -well plates. The plates were incubated for $48 \mathrm{~h}$ at $30^{\circ} \mathrm{C}$. Crackhealing tests were performed on $90 \times 15 \mathrm{~mm}$ petri dishes. The specimens were treated with $20 \mathrm{ml}$ of tap water, immersed in the half level, and covered by paper towels to keep them wet, and then cured at $25^{\circ} \mathrm{C}$. After the curing, the specimens were dried and cracked by a screwdriver and a hand hammer. For healing the crack, specimens were fixed by parafilm, immersed in the half level, and stocked at the $25^{\circ} \mathrm{C}$. Crack-healing measurements were processed using the UVP Colony Doc-It Imaging station (Analytik Jena, German) and a microscope (Imager A1, Zeiss, German). 


\section{Results}

One-Factor-at-a-Time Method for Screening Growth and Sporulation Substrates

DOE is generally divided into screening and optimization processes. The OFAT method was employed as the first screening method in this study to identify the low-cost substrate that most significantly contributed to the observed results, i.e., the one that best allows the AK13 strain to grow and sporulate. $\mathrm{NaCl}$, which is a component of the M9 medium, was not added in the present study because $\mathrm{Na}_{2} \mathrm{CO}_{3}$ was added instead to increase the $\mathrm{pH}$ of the tested media to $10.5 \pm 0.2$ at a concentration of $1 \%$ and to supply $\mathrm{Na}^{+}$[29].

In a first screening experiment, 21 agricultural products and byproducts were individually added to the M9 culture medium, and the number of vegetative cells was recorded $24 \mathrm{~h}$ after inoculation and the number of spores recorded after $72 \mathrm{~h}$. The purpose of this experiment was to select the substrates that best promoted the growth of the AK13 strain from among the 21 agricultural products. The M9 medium, without the addition of any substrate, was used as a control, with glucose and $\mathrm{NH}_{4} \mathrm{Cl}$ added as the sole carbon and nitrogen sources, respectively (Fig. 1A). In the control medium, the AK13 strain exhibited very little growth after $24 \mathrm{~h}$ of inoculation and produced no observable spores. For the tested substrates, barley malt powder, wheat bran, mixed grain powder, and glutinous rice flour were the four that produced the highest number of spores. These were followed by king oyster mushroom, mungbean flour, and beef seasoning. No spores were formed in the media supplemented with corn flour, potato flour, or corn syrup, probably because the nutrients essential for sporulation were lost during the refining process. The AK13 strain died in the M9 media containing rice bran and coffee powder, as indicated by the lower number of vegetative cells $(\mathrm{CFU} / \mathrm{ml})$ compared to the control M9 medium. In summary, wheat bran, barley malt powder, mixed grain powder, and glutinous rice flour were selected as the low-cost substrates best suited to the promotion of both the growth and sporulation of the AK13 strain.

\section{Screening of Major Substrates for Growth Using a two- Level Full Factorial Design}

A Pareto chart illustrates the standardized statistical significance of the main effects of individual factors and the interaction between or among two to four factors. In Fig. $1 \mathrm{~B}$, the $\mathrm{ABCD}$ and $\mathrm{BCD}$ interactions with a $p$-value lower than 0.05 were pooled. A p-value higher than 0.05 when the significance level $(\alpha)$ is set at $95 \%$ indicates that the variable has no effect on the dependent variable, and the probability of it being mistakenly classified as significant is higher than $5 \%$. The barley malt powder (B), the mixed grain powder $(C)$, and their interactions (BC) were statistically significant, with the contribution of the individual substrates to the growth of the AK13 strain the highest for the barley malt powder and the mixed grain powder, followed by wheat bran (A) and glutinous rice flour (D). The glutinous rice flour thus showed the weakest main effect of the four factors. The interactions involving glutinous rice flour $(\mathrm{AD}, \mathrm{BD}, \mathrm{ABD}$, and $\mathrm{BCD})$ were also low in terms of their effect on growth of AK13 strain. Therefore, barley malt powder and mixed grain powder were selected as the two substrates that contributed most to the growth of the AK13 strain.

\section{Optimization of the Main Substrates Using a Central Composite Design}

A central composite design is an optimization process that allows the optimal concentration of the main substrates to be identified. We attempted to determine whether the barley malt powder and mixed grain powder, the two substrates selected after the two screening processes described above, maximized the growth and spore yields of the AK13 strain within a concentration range of 1.38 to $5.62 \%$. Changes in the growth rate $(\mathrm{A})$ and sporulation (B) as a function of the concentration of the barley malt powder and mixed grain powder are presented in Fig. 2. A darker green indicates a greater number of vegetative cells or spores at that concentration level. As shown in Fig. 2B, the optimal concentration that maximized spore production was $1.38 \%$ for both the barley malt powder and mixed grain powder. An increase in the substrate concentration had opposite effects on the growth and sporulation levels of AK13, with the growth rate increasing and the sporulation rate decreasing as the substrates concentration decreased.

As with the OFAT approach, the number of vegetative cells was measured after $24 \mathrm{~h}$ and the number of spores at $72 \mathrm{~h}$. Based on the two measurements, the following two regression equations were calculated:

$\mathrm{Y}_{\mathrm{G}}=-103.82+31.06 \mathrm{X}_{1}+32.01 \mathrm{X}_{2}-1.72 \mathrm{X}_{1}^{2}-2.120 \mathrm{X}_{2}^{2}-$ $3.26 \mathrm{X}_{1} \mathrm{X}_{2}$

$$
Y_{S}=37.43-8.59 X_{1}-8.45 X_{2}+0.62 X_{1}^{2}+0.50 X_{2}^{2}+0.84 X_{1} X_{2}
$$



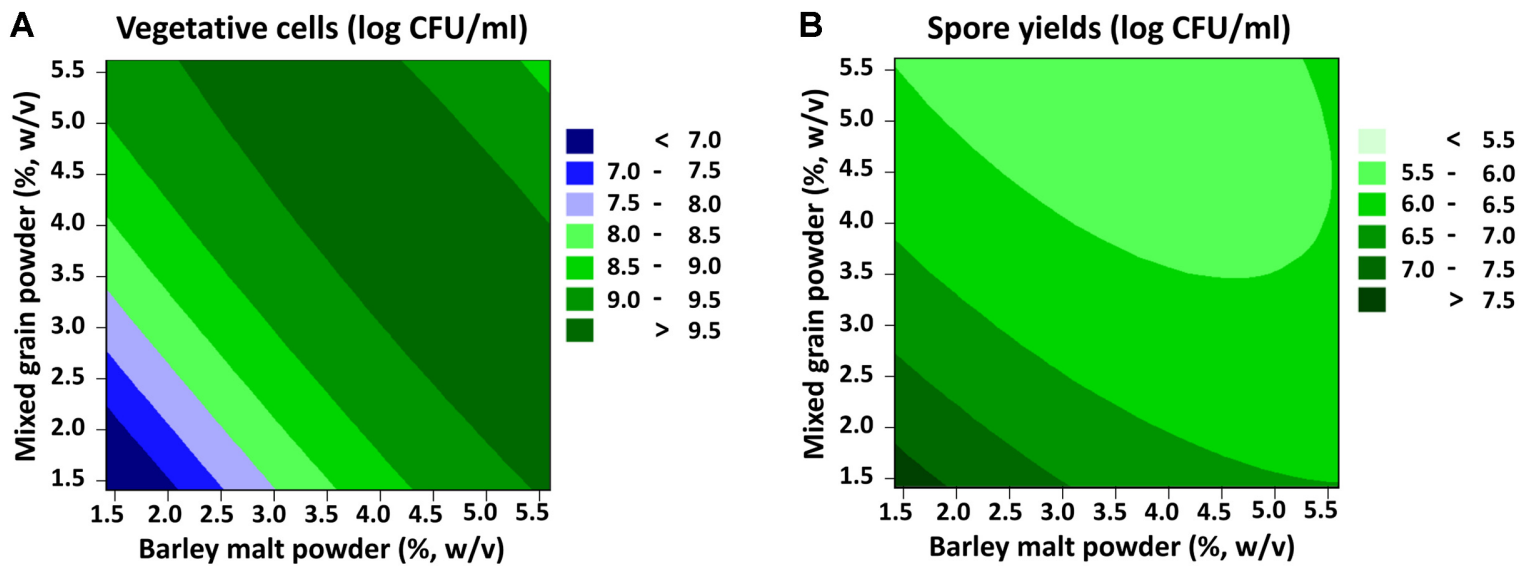

Fig. 2. Contour plot derived from the statistical analysis of the central composite design.

(A) Growth of vegetative cells at various concentrations of the low-cost substrates barley malt powder and mixed grain powder. (B) Spore yields based on the concentrations of the two main substrates. In both (A) and (B), more vegetative cells or spores were produced at concentrations closer to dark green than those of a lighter color.

$\mathrm{Y}_{\mathrm{G}}$ and $\mathrm{Y}_{\mathrm{S}}$ are the dependent variables (growth and sporulation, respectively). The R-square value for growth and sporulation was $85.5 \%$ and $68.3 \%$, respectively, which means that $85.5 \%$ and $68.3 \%$ of the experimental results for growth and sporulation were explained by the quadratic equations above, which was formed by substituting the corresponding concentrations into the independent variables of the regression equations. In other words, the above regression equation can explain as much as $85.5 \%$ and $68.3 \%$ of the actual data of growth and sporulation. The other $14.5 \%$ and $31.7 \%$ of the variation may be the result of noise or external factors.

\section{Comparison of the Growth Rates and Spore Yields for the Proposed Low-Cost Medium with Those for DSM}

To objectively evaluate the effectiveness of our proposed low-cost medium, it was compared with DSM in terms of the number of vegetative cells and spores produced. After $72 \mathrm{~h}$ of incubation, the bacterial growth and spore yields were $3.08 \pm 0.38 \times 10^{8} \mathrm{CFU} / \mathrm{ml}$ and $1.25 \pm 0.12 \times 10^{8} \mathrm{CFU} /$ $\mathrm{ml}$ for the proposed medium and $7.8 \pm 0.31 \times 10^{7} \mathrm{CFU} / \mathrm{ml}$ and $1.2 \pm 0.29 \times 10^{7} \mathrm{CFU} / \mathrm{ml}$ for DSM, respectively. Thus, the low-cost medium produced 3.9 and 10.4 times more vegetative cells and spores, respectively, than did the DSM. The sporulation rates were $40.4 \%$ and $14.9 \%$ for the lowcost medium and DSM, respectively, which means that, in the former, the vegetative cells of the AK13 strain were 2.7 times more likely to become spores. In terms of sporepowder yields after the spray-drying process, $1.76 \mathrm{~g} / 1$ of powder was harvested using DSM compared to $8.88 \mathrm{~g} / 1$ using the economical medium, an approximate 5-fold increase. More spore powder can be obtained when spray drying the proposed medium compared to DSM because the former has more solids that can serve as carriers.

\section{Selection of Nutrients and Quantification of Calcium Carbonate Precipitation}

Nutrients need to be mixed with the cement powder so that AK13 spores can germinate within the mortar. Adjusting the nutrient ratio can lead to more sustained AK13 growth. The ratio of yeast extract to calcium lactate was selected with reference to the modified B4 medium (Fig. 3A). The AK13 strain was added at $1 \times 10^{6} \mathrm{CFU} / \mathrm{ml}$ to a $250-\mathrm{ml}$ flask and incubated for four days at $30^{\circ} \mathrm{C}$. The tested ratios of yeast extract to calcium lactate were $0.4: 0.25,0.4: 0.4$, and $0.4: 0.8$. The ratio of $0.4: 0.25$ produced a cell count of $7.33 \times 10^{7} \mathrm{CFU} / \mathrm{ml}$ and $0.94 \mathrm{mg} / \mathrm{ml}$ of calcium carbonate precipitate, both of which were lower than the $1.56 \times 10^{8} \mathrm{CFU} / \mathrm{ml}$ and $1.29 \mathrm{mg} / \mathrm{ml}$ for the 0.4:0.4 ratio, respectively. The 0.4:0.8 ratio yielded a cell count of $9.42 \times$ $10^{7} \mathrm{CFU} / \mathrm{ml}$ and $1.59 \mathrm{mg} / \mathrm{ml}$ of calcium carbonate precipitate, meaning that the highest calcium lactate concentration led to the greatest precipitation of calcium carbonate in the medium.

While this precipitation rate is important, a high cell count that is sustained over time is also vital in harsh conditions. To test this, the AK13 strain was grown and calcium carbonate precipitated in the modified B4 medium (Fig. 3B). The cell count and calcium carbonate on day 0 were $1.0 \times 10^{6} \mathrm{CFU} / \mathrm{ml}$ and $0 \mathrm{~g} / \mathrm{ml}$, respectively. After 1 

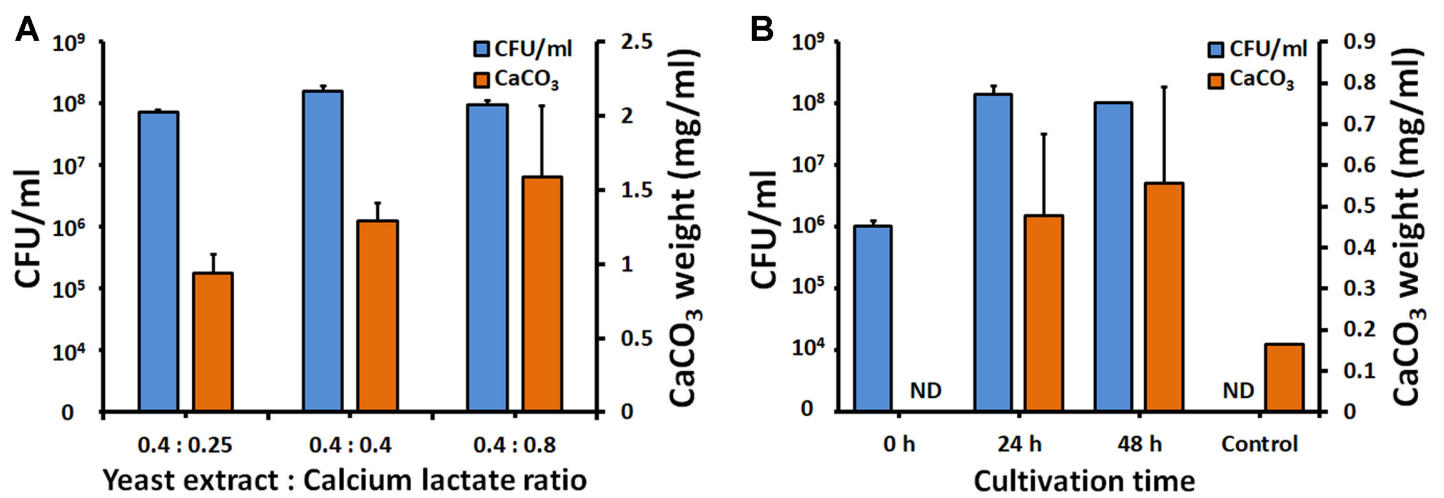

Fig. 3. Selection of the nutrient ratio and quantification of calcium carbonate.

(A) Selection of the nutrient ratio based on $\mathrm{CFU} / \mathrm{ml}$ and calcium carbonate. In mixing the AK13 and cement paste with the nutrients, the survival of AK13 was tested at yeast extract and calcium lactate ratios of 0.4:0.25, 0.4:0.4, and 0.4:0.8. (B) Quantification of calcium carbonate precipitation by AK13 in the modified (0.4:0.4 ratio) B4 medium. The control was not inoculated with AK13 and agitated for two days under the same conditions. ND: not detected.

day of incubation, the cell count was $1.40 \times 10^{8} \mathrm{CFU} / \mathrm{ml}$, and the precipitate was $0.47 \pm 0.19 \mathrm{mg} / \mathrm{ml}$. After two days, AK13 exhibited a cell count of $1.02 \times 10^{8} \mathrm{CFU} / \mathrm{ml}$ and a precipitation rate of $0.55 \pm 0.23 \mathrm{mg} / \mathrm{ml}$. In the control sample, which was not inoculated with AK13, calcium carbonate precipitation was three times lower than the two-day AK13 sample when agitated under the same conditions.

\section{In situ Survival Test and Crack-Healing Observations}

Survival tests confirmed that viable spores were present in the AK13-containing mortar. As observed under a microscope, AK13 germinated and precipitated calcium

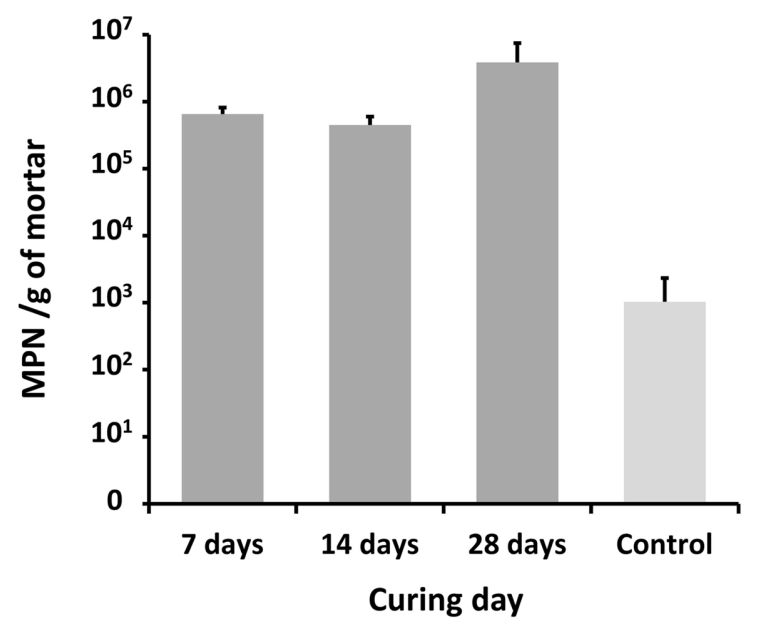

Fig. 4. MPN test in the mortar mixed with AK13 spores. Control specimens were cured for 28 days and consist of cement, water, and standard sand. carbonate in the cracks. After seven days of curing, the number of germinated AK13 cells in the mortar samples was $6.5 \times 10^{5} \mathrm{CFU} / \mathrm{g}$, compared to $4.5 \times 10^{5}$ and $3.8 \times 10^{6}$ $\mathrm{CFU} / \mathrm{g}$ after 14 days and 28 days, respectively (Fig. 4). Five arbitrary crack points were selected on each mortar specimen and observed for 28 days. The mortar specimens mixed with the spore powder were cured by being immersed completely underwater for 14 days and 28 days. Those specimens cured for 14 days exhibited cracks with a length that ranged from $0.25 \pm 0.03 \mathrm{~mm}$ to $0.14 \pm 0.06 \mathrm{~mm}$. The cracks on the 14-day sample 1 (S1; Fig. 5A) and sample 3 (S3) were healed after 14 days in a wet state at a rate of $0.13 \mathrm{~mm}$ and $0.10 \mathrm{~mm}$ per week, respectively (Fig. 5C). Because sample 2 (S2) had the widest crack of any sample $(0.31 \mathrm{~mm})$, healing was not observed for this specimen. The samples 4, 5, and 6 cured for 28 days (S4, S5, and S6, respectively) had cracks that ranged from $0.12 \pm 0.02 \mathrm{~mm}$ to $0.18 \pm 0.03 \mathrm{~mm}$ (Fig. 5D). S5 and S6 had crack widths of 0.12 $\pm 0.02 \mathrm{~mm}$ and $0.17 \pm 0.04 \mathrm{~mm}$, respectively, and were healed by AK13 calcium carbonate precipitation within a week, while the crack on S4 was covered by calcium carbonate within seven days, unlike the control (Fig. 5B). Cracks below $0.29 \mathrm{~mm}$ were healed in 14 days by the AK13 strain.

\section{Discussion}

To the best of our knowledge, this is the first study to develop a low-cost medium for the production of bacterial self-healing concrete using screening and optimization processes in accordance with the principles of the DOE 

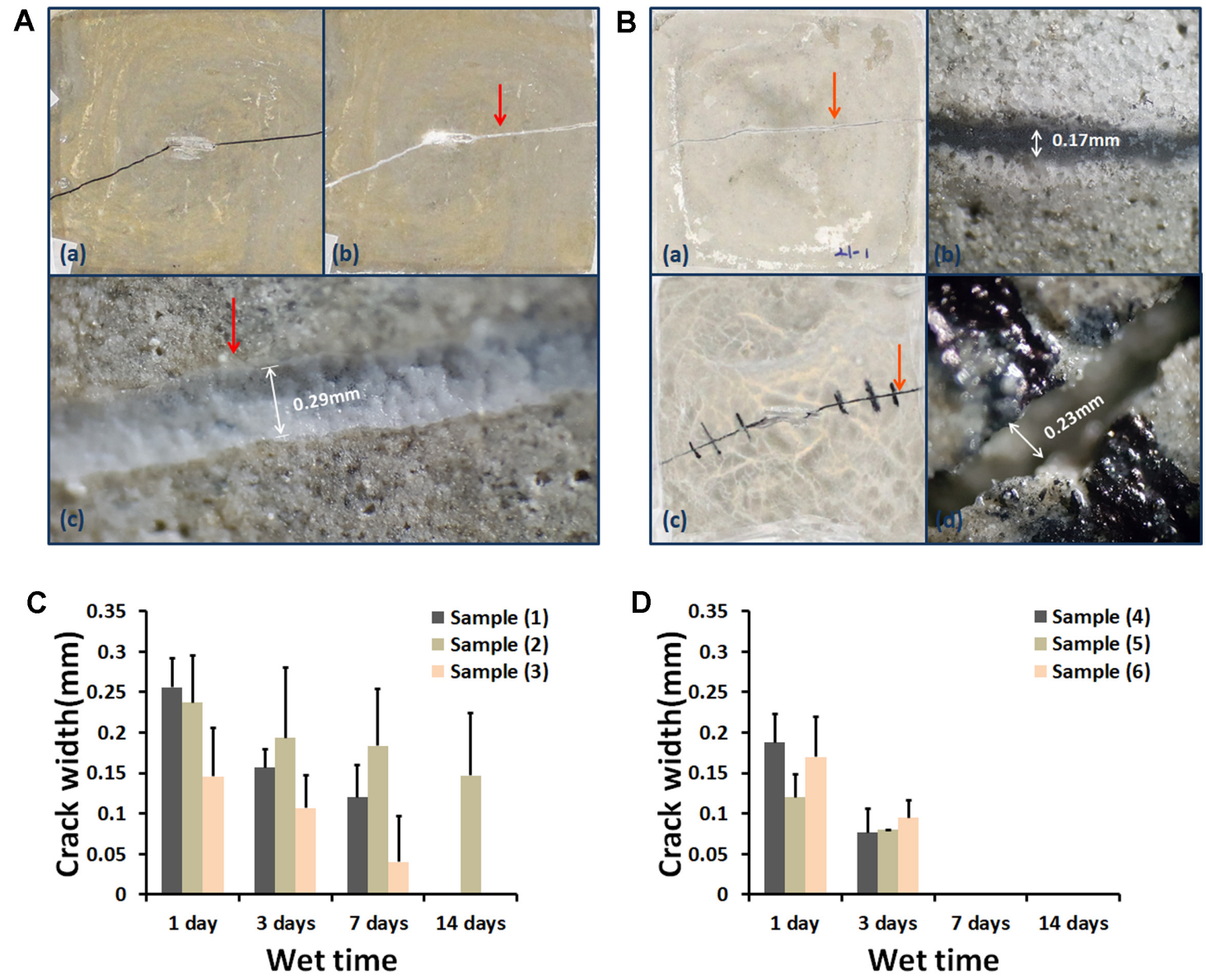

Fig. 5. Crack healing visualization.

(A) Images of 14-day sample 1 (S1) observed using a UVP Colony Doc-It imaging station and a fluorescence microscope. (a) and (b) are the 1-day and 14-day wet times, respectively. Calcium carbonate was precipitated on the crack. The red arrow indicates the calcium carbonate precipitation point at a magnification of 100× (c). (B) Images of sample 4 (S4) cured for 28 days and the control specimen cured for 7 days. S4 was observed using a UVP Colony Doc-It imaging station (a). The red arrow indicates the parts of S4 observed with a microscope at $\times 100$ magnification (b). (c) showed the control specimen that was 7-day wet times. (d) is a control specimen observed at a magnification of 100x. The crack of the control specimen is also shown (the red arrow at the bottom). The white markers illustrate the crack width. (C) Crack width of the 14-day samples. (D) Crack width of the 28-day samples.

methodology. The Plackett-Burman design (PBD) has been widely studied as an initial screening process, with more than 22,000 studies listed on Google Scholar employing this method [30]. PBD is a method of gathering materials to be sorted into one flask at a time by changing concentrations levels of each of them and is often considered to be more efficient than the OFAT approach, though this may not be true in certain cases [31]. As shown in Fig. 1A, the growth of the AK13 strain was inhibited by rice bran, probably because of its antibacterial activity, as reported for Bacillus cereus [32]. In addition, the AK13 strain was killed when mixed with coffee powder, which contains aromatic and phenolic compounds, such as protocatechuic acid and caffeic acid, which can disrupt the function of cell membranes and exert antimicrobial activity [33]. Therefore, if these two toxic substances were mixed with other lowcost substrates, the AK13 strain would hardly survive, and further experimentation would have been required to determine which substrates were toxic. PBD is also a resolution III design in which the main effects are aliased with two-way interactions, as in the OFAT approach [3436]. Therefore, we applied the OFAT method instead of $\mathrm{PBD}$ in the selection process at the risk of increasing the inefficiency. In Fig. 1A, spores were rare in the control medium, confirming that the production of spores was not affected by the calcium $\left(\mathrm{CaCl}_{2}\right)$ or magnesium sources 
$\left(\mathrm{MgSO}_{4}\right)$ in the M9 medium but rather was induced by the components of the low-cost substrates $[12,37]$.

As a self-healing agent, bacteria such as Bacillus sphaericus, B. megaterium, and Sporosarcina pasteurii have been studied for their ability to precipitate calcium carbonate in concrete [22]. Calcium carbonate precipitation has the advantage of not only acting as a self-healing agent but also increasing the durability of the concrete [38]. To apply bacteria as a self-healing agent in a concrete environment, alkaliphilic and spore-forming abilities are essential [39]. AK13 is suitable for use in concrete as a selfhealing agent because it can survive at $\mathrm{pH} 13$. Spray drying is a more economically efficient method of transforming aqueous suspensions of spores into a solid spore powder than freeze-drying; as such, it has been commercially applied in a number of fields, including agriculture, pharmaceuticals, and probiotics production [40, 41]. Spore powder production is an important factor for practical application because the number of spores being mixed in cement can be controlled without changing the water/ cement $(\mathrm{W} / \mathrm{C})$ ratio $[42,43]$. Unlike other studies that have produced bacteria-containing concrete with spore solutions, the spore concentration can be adjusted using spore powder [40].

In addition, the yeast extract and calcium lactate ratio was optimized at 0.4:0.4 in the present study, but the specific nutrient levels were not tested. Higher concentrations of calcium lactate increased the calcium carbonate precipitation, but this did not promote the growth of AK13. The optimal growth of AK13 is particularly important for the development of self-healing concrete. In addition, immersing the AK13-containing mortar in water demonstrated that AK13 was able to precipitate calcium carbonate in a harsh environment with oxygen restriction. Even greater calcium carbonate precipitation is predicted when the proposed bioconcrete is not immersed in water. Because the volume of a crack can be inferred from its width, the healing rate can be determined using the width of the crack. Crack-healing observation tests confirmed the potential of AK13 as a selfhealing material based on the crack healing and sealing abilities of AK13-containing mortar. The crack-healing measurement is essential before any strength test of the AK13-containing concrete can be conducted. In addition, the AK13 strain produced non-ureolytic calcium carbonate precipitation, which represents a more eco-friendly reaction with a faster healing time than ureolytic calcium carbonate precipitation [44]. The cracks on the mortar samples under $0.29 \mathrm{~mm}$ in width were covered by calcium carbonate after 14 days.

Because B. sphaericus and S. pasteurii are grown at $\mathrm{pH} 7-$ 11 , and 5-11, respectively, carriers must be used in concrete ( $\mathrm{pH}$ 12-13) [45]. In contrast, Bacillus sp. AK13 can be applied to mortar without carriers because AK13 is a sporeforming and alkaliphilic organism that can survive at $\mathrm{pH}$ 13 [22]. For other bacteria, micro-encapsulated spores, hydrogel-encapsulated bacteria, silica gel or polyurethane prepolymer-based carriers, expanded perlite, and expanded clay have been studied with a view to enhancing their survival rate [44, 46-49]. Carriers must be used to increase strength of bioconcrete by binding with the cement and to decrease water permeability by concentrating calcium carbonate precipitation at the cracking site. Finally, further strength and water permeability tests should be carried out on the bioconcrete mixed with AK13-containing carriers.

\section{Acknowledgements}

This research was supported by a grant (19SCIPB103706-05) from Construction Technology Research Program funded by Ministry of Land, Infrastructure and Transport of Korean government and a grant from the National Institute of Biological Resources (NIBR), funded by the Ministry of Environment (MOE) of the Republic of Korea (NIBR201920201).

\section{Conflict of Interest}

The authors have no financial conflicts of interest to declare.

\section{References}

1. Celik K, Jackson M, Mancio M, Meral C, Emwas AH, Mehta P, et al. 2013. High-volume natural volcanic pozzolan and limestone powder as partial replacements for portland cement in self-compacting and sustainable concrete. Cement. Concrete. Compo. 45: 136-147.

2. Meyer C. 2008. The greening of the concrete industry. Cement. Concrete. Comp. 31: 601-605.

3. Mignon A, Snoeck D, Dubruel P, Van Vlierberghe S, De Beli N. 2017. Crack mitigation in concrete: superabsorbent polymers as key to success? Materials 10(3): 237.

4. Won JP, Kim SH, Lee SJ, Choi S. 2013. Shrinkage and durability characteristics of eco-friendly fireproof highstrength concrete. Constr. Build. Mater. 40: 753-762.

5. Hager MD, Greil P, Leyens C, Van Der Zwaag S, Schubert US. 2010. Self-healing materials. Adv. Mater. 22: 5323-5430. 
6. Williams KA, Dreyer DR, Bielawski CW. 2008. The underlying chemistry of self-healing materials. Mrs. Bull. 33: 759-765.

7. Palin D, Wiktor V, Jonkers HM. 2017. A bacteria-based selfhealing cementitious composite for application in lowtemperature marine environments. Biomimetics 14:2(3). pii: E13.

8. Lee YS, Kim HJ, Park W. 2017. Non-ureolytic calcium carbonate precipitation by Lysinibacillus sp. YS11 isolated from the rhizosphere of Miscanthus sacchariflorus. J. Microbiol. 55: 440-447.

9. Dick J, De Windt W, De Graef B, Saveyn H, Van der Meeren P, De Belie N, et al. 2006. Bio-deposition of a calcium carbonate layer on degraded limestone by Bacillus species. Biodegration 17: 357-367.

10. Jonkers HM, Thijssen A, Muyzer G, Copuroglu O, Schlangen E. 2010. Application of bacteria as self-healing agent for the development of sustainable concrete. Ecol. Eng. 36: 230-235.

11. Lee YS, Park W. 2018. Current challenges and future directions for bacterial self-healing concrete. Appl. Microbiol. Biotechnol. 102: 3059-3070.

12. Chen ZM, Li Q, Liu HM, Yu N, Xie TJ, Yang MY, et al. 2010. Greater enhancement of Bacillus subtilis spore yields in submerged cultures by optimization of medium composition through statistical experimental designs. Appl. Microbiol. Biotechnol. 85: 1353-1360.

13. Manzoor A, Qazi JI, Haq IU, Mukhtar H, Rasool A. 2017. Significantly enhanced biomass production of a novel biotherapeutic strain Lactobacillus plantarum (AS-14) by developing low cost media cultivation strategy. J. Biol. Eng. 11: 17.

14. Coghetto CC, Vasconcelos CB, Brinques GB, Ayub MA. 2016. Lactobacillus plantarum BL011 cultivation in industrial isolated soybean protein acid residue. Braz. J. Microbiol. 47: 941-948.

15. Lavari L, Páez R, Cuatrin A, Reinheimer J, Vinderola G. 2014. Use of cheese whey for biomass production and spray drying of probiotic lactobacilli. J. Dairy. Res. 81: 267-274.

16. Khardziani T, Kachlishvili E, Sokhadze K, Elisashvili V, Weeks R, Chikindas ML, et al. 2017. Elucidation of Bacillus subtilis KATMIRA 1933 potential for spore production in submerged fermentation of plant raw materials. Probiotics Antimicrob. Proteins 9: 435-443.

17. Achal V, Mukherjee A, Basu PC, Reddy MS. 2009. Lactose mother liquor as an alternative nutrient source for microbial concrete production by Sporosarcina pasteurii. J. Ind. Microbiol. Biotechnol. 36: 433-438.

18. Yoosathaporn S, Tiangburanatham P, Bovonsombut S, Chaipanich A, Pathom-Aree W. 2016. A cost effective cultivation medium for biocalcification of Bacillus pasteurii KCTC 3558 and its effect on cement cubes properties. Microbiol. Res. 186-187: 132-138.

19. Joshi S, Goyal S, Reddy MS. 2018. Corn steep liquor as a nutritional source for biocementation and its impact on concrete structural properties. J. Ind. Microbiol. Biotechnol. 45: 657-667.

20. Wang J, Ersan YC, Boon N, De Belie N. 2016. Application of microorganisms in concrete a promising sustainable strategy to improve concrete durability. Appl. Microbiol. Biotechnol. 100: 2993-3007.

21. Joshi S, Goyal S, Mukherjee A, Reddy MS. 2017. Microbial healing of cracks in concrete: A review. J. Ind. Microbiol. Biotechnol. 44: 1511-1525.

22. Lee YS, Park W. 2019. Enhanced calcium carbonate-biofilm complex formation by alkali-generating Lysinibacillus boronitolerans YS11 and alkaliphilic Bacillus sp. AK13. AMB Express. 9: 49.

23. Subra P, Jestin P. 2000. Screening design of experiment (DOE) applied to supercritical antisolvent process. Ind. Eng. Chem. Res. 39: 4178-4184.

24. Antony J. 2014. Design of Experiments for Engineers and Scientists, pp. 63-85. 2nd Ed. School of Management and Languages, Heriot-Watt University, Edinburgh, Scotland, UK.

25. Sekar A, Kim M, Jeong HC, Kim K. 2018. Strain selection and optimization of mixed culture conditions for Lactobacillus pentosus K1-23 with antibacterial activity and aureobasidium pullulans NRRL 58012 producing immune-enhancing $\beta$-glucan. J. Microbiol. Biotechnol. 28: 697-706.

26. Monteiro SM, Clemente JJ, Henriques AO, Gomes RJ, Carrondo MJ, Cunha AE. 2008. A procedure for high-yield spore production by Bacillus subtilis. Biotechnol Prog. 21: 1026-1031.

27. Ren H, Su YT, Guo XH. 2018. Rapid optimization of spore production from Bacillus amyloliquefaciens in submerged cultures based on dipicolinic acid fluorimetry assay. $A M B$ Express. 8: 21.

28. Boquet E, Boronat A, Ramos-Cormenzana A. 1973. Production of calcite (calcium carbonate) crystals by soil bacteria is a general phenomenon. Nature 246: 527-529.

29. Horikoshi K. 1996. Alkaliphiles - from an industrial point of view. FEMS Microbiol. Rev. 18: 259-270.

30. Chand N, Lonsane BK. 1994. Use of Plackett-Burman design for rapid screening of several nitrogen sources, growth/ product promoters, minerals and enzyme inducers for the production of alpha-galactosidase by Aspergillus niger MRSS 234 in solid state fermentation system. Bioprocess Eng. 10: 139-144.

31. Jo JH, Lee DS, Park D, Choe WS, Park JM. 2007. Optimization of key process variables for enhanced hydrogen production by Enterobacter aerogenes using statistical methods. Bioresour. Technol. 99: 2061-2066.

32. Almeida AA, Farah A, Silva DA, Nunan EA, Glória MB. 2015. Antibacterial activity of coffee extracts and selected coffee chemical compounds against enterobacteria. J. Agric. Food. Chem. 54: 8738-8743. 
33. Trang H, Pasuwan P. 2018. Screening antimicrobial activity against pathogens from protein hydrolysate of rice bran and Nile Tilapia by-products. Int. Food Res. J. 25: 2157-2163.

34. Olivieri AC, Magallanes JF. 2012. Uncovering interactions in Plackett-Burman screening designs applied to analytical systems. A Monte Carlo ant colony optimization approach. Talanta 97: 242-248.

35. Kulahci M, Bisgaard S. 2007. Partial confounding and projective properties of Plackett-Burman designs. Qual. Reliab. Eng. Int. 23: 791-800.

36. Lim HS, Cha IT, Roh SW, Shin HH, Seo MJ. 2017. Enhanced production of gamma-aminobutyric acid by optimizing culture conditions of lactobacillus brevis HYE1 isolated from kimchi, a Korean fermented food. J. Microbiol. Biotechnol. 27: 450-459.

37. Shi F, Zhu Y. 2007. Application of statistically-based experimental designs in medium optimization for spore production of Bacillus subtilis from distillery effluent. BioControl. 52: 845-853.

38. Kim HK, Park SJ, Han JI, Lee HK. 2012. Microbially mediated calcium carbonate precipitation on normal and lightweight concrete. Constr. Build. Mater. 38: 1073-1082.

39. De Belie N, Gruyaert E, Al-Tabbaa A, Actonaci P, Baera C, Bajare $\mathrm{D}$, et al. 2018. A review of self-healing concrete for damage management of structures. Adv. Mater. 5: 17.

40. Huang S, Vignolles ML, Chen XD, Le Loir Y, Jan G, Schuck P, et al. 2017. Spray drying of probiotics and other food-grade bacteria: A review. Trends Food Sci. Tech. 63: 1-17.

41. Chumthong A, Wiwattanapatapee R, Viernstein H, Pengnoo A, Kanjanamaneesathian M. 2016. Spray-dried powder of
Bacillus megaterium for control of rice sheath blight disease: Formulation protocol and efficacy testing in laboratory and greenhouse. Cereal Res. Commun. 44: 131-140.

42. Goto S, Roy D. 1981. The effect of $\mathrm{w} / \mathrm{c}$ ratio and curing temperature on the permeability of hardened cement paste. Cement. Concrete. Res. 11: 575-579.

43. Wang J, Jonkers HM, Boon N, De Belie N. 2017. Bacillus sphaericus LMG 22257 is physiologically suitable for selfhealing concrete. Appl. Microbiol. Biotechnol. 101: 5101-5114.

44. Wang J, Soens H, Verstraete W, De Belie N. 2014. Selfhealing concrete by use of microencapsulated bacterial spores. Cem. Concr. Res. 56: 139-152.

45. Achal V, Mukherjee A, Basu PC, Reddy MS. 2009. Strain improvement of Sporosarcina pasteurii for enhanced urease and calcite production. J. Ind. Microbiol. Biotechnol. 36:981-988.

46. Wang J, Snoeck D, Vlierberghe S, Verstraete W, De Belie N. 2014. Application of hydrogel encapsulated carbonate precipitating bacteria for approaching a realistic self-healing in concrete. Constr. Build. Mater. 68: 110-119.

47. Wang J, Van Tittelboom K, De Belie N, Verstraete W. 2012. Use of silica gel or polyurethane immobilized bacteria for self-healing concrete. Constr. Build. Mater. 26: 532-540.

48. Alazhari M, Sharma T, Heath A, Cooper R, Paine K. 2018. Application of expanded perlite encapsulated bacteria and growth media for self-healing concrete. Constr. Build. Mater. 160: 610-619.

49. Wiktor V, Jonkers HM. 2011. Quantification of crack-healing in novel bacteria-based self-healing concrete. Cem. Concr. Compos. 33: 763-770. 